2. Andropoulos DB, Diaz LK, Fraser CD Jr, McKenzie ED, Stayer SA. Is bilateral monitoring of cerebral oxygen saturation necessary during neonatal aortic arch reconstruction? Anesth Analg. 2004;98:1267-72.

3. Andropoulos DB, Stayer SA, McKenzie ED, Fraser CD Jr. Regional low flow perfusion provides comparable blood flow and oxygenation to both cerebral hemispheres during neonatal aortic arch reconstruction. J Thorac Cardiovasc Surg. 2003;126:1712-7.
4. Andropoulos DB, Stayer SA, McKenzie ED, Fraser CD Jr. Novel cerebral physiologic monitoring to guide low flow cerebral perfusion during neonatal aortic arch reconstruction. J Thorac Cardiovasc Surg. 2003;125:491-9.

5. Kiraly L, Prodan Z. Continuous system perfusion via collaterals at moderate hypothermia in aortic arch repairs in neonates. Croat Med $J$. 2002;43:656-9.

\title{
Thoracic aortic aneurysm in a young infant with congenital aortic stenosis
}

Dante Picarelli, MD, ${ }^{a}$ Serrana Antunez, MD, ${ }^{a}$ Christian Kreutzer, MD, ${ }^{\mathrm{b}}$ Guillermo Touyá, MD, ${ }^{a}$ Diego Abdala, MD, ${ }^{\mathrm{a}}$ Luis Ligüera, MD, ${ }^{a}$ and Gabriel Echegaray, MD, ${ }^{a}$ Montevideo, Uruguay, and Buenos Aires, Argentina

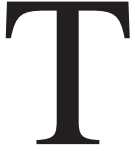
horacic aortic aneurysm is uncommon in pediatric patients. ${ }^{1,2}$ Its association with congenital valvar aortic stenosis is rarely seen in infants. ${ }^{3}$ To the best of our knowledge there have been no prior reports of surgical treatment of an aortic isthmus aneurysm in an infant with critical aortic stenosis.

We report our experience with this uncommon association in a 45-day-old infant who required aneurysmectomy and aortic balloon dilation.

\section{Clinical Summary}

Shortly after birth, congestive heart failure developed in a full-term male neonate weighing $3200 \mathrm{~g}$.

Doppler echocardiography revealed a critical valvular aortic stenosis with an adequate aortic annulus and left ventricle and a severely impaired ventricular function. At the level of the aortic isthmus, an "extremely dilated" ductus arteriosus with a bidirectional shunt was described.

On the second day of age, the patient underwent a successful percutaneous balloon valvotomy with a right carotid approach. The peak systolic gradient decreased from 80 to $30 \mathrm{~mm} \mathrm{Hg}$, and the ejection fraction was $25 \%$. The aortogram showed no evidence of residual aortic regurgitation but did show a pathologic saccular dilation of the lateral aspect of the aortic isthmus (Figure 1).

\footnotetext{
From the Division of Cardiac Surgery and Intensive Care Unit, Congenital Cardiac Unit, American Cardiac Center, American Hospital, ${ }^{a}$ Montevideo, Uruguay; and Division of Cardiac Surgery, Hospital de Niños Ricardo Gutierrez,' Buenos Aires, Argentina.

Received for publication Dec 9, 2006; accepted for publication Dec 14, 2006.

Address for reprints: Dante Picarelli, MD, Unidad de Cardiopatías Congénitas, Centro Cardiológico Americano, Sanatorio Americano, Isabelino Bosch 2469, Montevideo 11600 Uruguay (E-mail: picarelli54@hotmail. com).

J Thorac Cardiovasc Surg 2007;133:1098-9

$0022-5223 / \$ 32.00$

Copyright $\odot 2007$ by The American Association for Thoracic Surgery doi:10.1016/j.jtcvs.2006.12.018
}

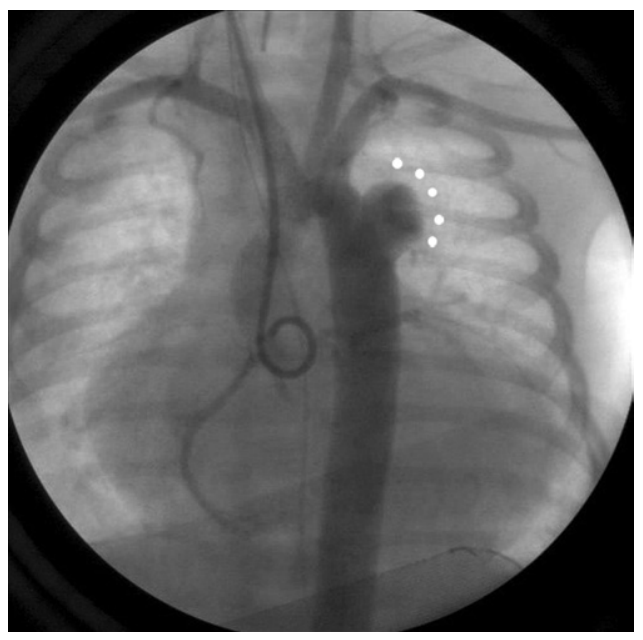

Figure 1. Aortogram showing a large aortic aneurysm involving the aortic isthmus.

Despite the risk of spontaneous aortic rupture or dissection, we decided to wait for left ventricular recovery before surgical repair was attempted. The infant remained in stable condition after treatment with diuretics, vasodilators, and digoxin.

Regular echocardiography surveillance did not show any sign of enlargement.

Six weeks after birth, when the left ventricular function partially improved (ejection fraction 40\%), we decided to perform the surgical correction.

The operation was performed without cardiopulmonary bypass through a standard left thoracotomy. Operative findings confirmed a saccular aneurysmatic dilation, measuring $18 \times 10$ $\mathrm{mm}$, located at the aortic isthmus. The ductus arteriosus was not involved, and the aortic wall was noted to be more fragile than normal, without adhesions to the lung, esophagus, or other mediastinal structures.

The aneurysm was dissected and handled with special care; the aorta was crossclamped between the left carotid and the subclavian 
arteries proximally and below the isthmus distally. After the ductus was divided, aneurysmectomy and end-to-end anastomosis were successfully performed. The patient made an uneventful recovery and was transferred 5 days after surgery to the original hospital in good condition.

Histopathology of the aortic tissue samples revealed fragmentation of elastic fibers, without inflammatory changes, along with areas of ground substance accumulation, which are characteristic of cystic medial necrosis.

\section{Discussion}

Thoracic aorta aneurysm is a rare lesion in the pediatric age group. ${ }^{1,2,4}$ It has usually been described in patients with connective disorders such as Marfan ${ }^{2,4}$ or Ehlers-Danlos ${ }^{1,5}$ syndrome, Kawasaki, or tuberous sclerosis. ${ }^{2}$ The proximal ascending aorta is most commonly affected..$^{3,4}$

Histopathology features are different depending on the location. ${ }^{5}$ The typical thoracic aneurysm is characterized by fragmentation of elastic fibers, without inflammatory changes, and areas of characteristic cystic medial necrosis. ${ }^{5}$ In contrast, the abdominal aneurysm is dominated by intimal atherosclerosis, chronic transmural inflammation, and remodeling of the media. ${ }^{5}$ In our patient the histologic findings confirmed the characteristic features of thoracic aneurysms.

Few cases associating aortic aneurysm and aortic stenosis have been reported in children. ${ }^{3,4}$ All of them were associated with an aneurysm of the proximal ascending aorta.

However, to the best of our knowledge, the association of congenital valvar aortic stenosis and aneurysm of the aortic isthmus requiring surgical treatment in a young infant has not been reported.

Umbilical catheterization has been advocated as a possible cause of mycotic aneurysm in newborns. ${ }^{2}$ Nevertheless, in our patient the absence of inflammatory changes in the histologic study and the aortic dilation found immediately after birth suggest another underlying cause. On the other hand, aortic wall injury, produced by the balloon catheter during the valvotomy procedure, could not be advocated as a possible cause of dissection because it was introduced retrogradely through the right carotid artery (Figure 1).
Other mechanisms of aneurysm formation, related to the diverse embryologic origin of cells, populating the segments of the aorta and having dissimilar structural properties and propensities have been proposed. ${ }^{4,5}$ In that sense, significant heterogeneity exists at the molecular level between the thoracic and abdominal aneurysm. ${ }^{5}$

In our patient the aortic isthmus aneurysm was asymptomatic, and the lesion was diagnosed incidentally by an aortogram performed to check the balloon valvotomy procedure. Doppler echocardiography was unable to describe the nature of the lesion.

The indication for surgical repair (despite no evidence of enlargement) was based on the fact that resection and end-to-end anastomosis are easier in infants because of the increasing experience with aortic arch repair in this age group, avoiding the need for cardiopulmonary bypass and composite graft. Moreover, because of the absence of adhesions in the lung, esophagus, and other mediastinal structures, handling the aneurysm was safer. Leaving the aneurysm without surgical treatment was not only a risk factor for rupture or dissection but also an additional risk for an eventual second valvotomy procedure.

In summary, we reported our experience with the successful treatment of a rare association in a young infant requiring two complementary procedures.

\section{References}

1. Conte S, Serraf A, Lacour-Gayet F, Bruniaux J, Planché C. Successful repair of thoracic aortic aneurysm in a child with Ehlers-Danlos syndrome. J Thorac Cardiovasc Surg. 1997;113:410-1.

2. Martinez L, Riera L, Avila LF, Riera LF, Stefanov S, Gutierrez M, et al Idiopathic abdominal aortic aneurysm in an 8 year old female patient. Angiologia. 2006;58:245-8.

3. Becker RM, Poirier NL, Collins GF, Rosales JK, Mulder DS. Cystic medial necrosis and dissecting aneurysm of the aorta in a child with congenital aortic stenosis. J Thorac Cardiovasc Surg. 1974;68:108-11.

4. Shah N, Kher A, Lahiri K, Kandalkar BM. Annuloaortic ectasia in two siblings. Indian Pediatr. 2002;39:395-8.

5. Absi TS, Sundt TM III, Tung WS, Moon M, Lee JK, Damiano RR, et al. Altered patterns of gene expression distinguishing ascending aortic aneurysms from abdominal aortic aneurysms: complementary DNA expression profiling in the molecular characterization of aortic disease. J Thorac Cardiovasc Surg. 2003;126:344-57. 